\title{
Implantation of Continuous Flow Pumps in Aortic Valve Position: Theoretical Advantages and Disadvantages
}

\author{
Enrique Seguel* \\ Universidad de Concepcion, Faculty of Medicine, Department of Surgery, Chile
}

${ }^{\star}$ Corresponding author: Enrique Seguel, Department of Surgery, Faculty of Medicine, University of Concepcion, Roosevelt Ave. S/N, Concepción, Chili; Tel: +569 98832233; E-mail: enseguel@udec.cl

Received: July 31, 2019; Accepted: August 07, 2019; Published: September 28, 2019;

\begin{abstract}
Left ventricle assist devices has become an alternative in treatment of cardiac failure. They are used as bridges to recovery, heart trasplant or destination therapy. There are two principal types of circulatory support systems: pulsed flow pumps and continuous flow pumps. The latter correspond to small turbines that levitate in a magnetic field and driving the blood from the left ventricle into the aorta. The common configuration consist in an inflow cannula in the left ventricular apex, a turbine and an output tube graft anastomosed to the ascending or descending aorta. All they are controlled and powered electrically by a wire from the outside. Despite this advances, there remains a high rate of complications. Including anatomical problems (pocket, inflow cannula, outflow graft), technical problems (bleeding, adhesions), infections, thrombosis, embolism and aortic valve problems. To reduce some of these complications, some investigators have developed the concept of aortic intravalvular pump (Valvo - pump). The prototypes are in the experimental stage and are not adapted to use for extended periods or in humans. The theoretical advantages and disadvantages of the implantation of a continuous flow pump in aortic valve position are discussed, and the first experimental models are described.
\end{abstract}

Keywords: Cardiac Surgery, Heart Failure, Heart Transplant, Left Ventricle Assist Devices, Valvo Pump

\section{Introduction}

Heart failure has become one of the most common causes of hospitalization in developed countries. It accounts for $5 \%$ of emergency hospitalizations and about $10 \%$ of all hospitalizations in Europe. According to statistics from the European Society of Cardiology, $1-2 \%$ of the european adult population currently suffer from heart failure. The incidence increases to $10-20 \%$ in people over 75 years and heart failure remains a leading cause of death. Finally, because of the aging of the population, the prevalence is increasing [1]. The prognosis remains poor, with a mortality of $50 \%$ at 4 years. Current medical treatments, ventricular re-synchronization, conventional cardiac surgery (coronary or valvular) and ventricular remodeling surgery have improved the overall prognosis of this disease, but for a significant number of patients, the only treatment possible remains the heart transplantation [2]. The results of transplantation are very encouraging, with one-year survival of $77 \%$, five years of $67 \%$, and ten years of 53\% [3]. Unfortunately the number of donors has decreased and the number of patients on the waiting list continues to increase. As a result, there is a real lack of grafts to satisfy demand [4].

Since the early 1960s, circulatory assistances have been developed to support the function of the left ventricle. All the advances made in this field have made it possible to move from extracorporeal circulation to pneumatic, electromechanical implantable mechanical assistance systems, and even the appearance of a total artificial heart and continuous flow assistance [5]. Rose and coworkers of the REMATCH study investigators compared 61 patients with nontransplantable, medically treated terminal heart failure versus 68 patients who received implantable mechanical assistance (Heartmate, Thoratec ${ }^{\circledR}$ ). At two years, the survival of the group under assistance was $23 \%$ against $8 \%$ in the group treated medically $(p=0.09)$ [6]. There are currently two main implantable circulatory assistance systems: pulsatile flow and axial flow circulatory assistances.

Pulsatile flow assistances used pneumatic energy to fill and empty cavities similar to ventricles. Flow is directed through uni - directional inlet and outlet valves that provide pulsed flow and "physiological" cardiac output. This systems can be used to assist both ventricles. Pulsatile flow assistance is now virtually abandoned in favor of axial pumps, because of their smaller size, lower thrombotic risk, and better energy efficiency, even if the reduction or abolition of the pulsatility has been criticized. In all cases, these axial flow pump systems are composed of an inlet cannula implanted at the apex of the left ventricle, an electric pump and an outlet tube anastomosed directly to the ascending aorta or down. They can be implanted by sternotomy or by thoracotomy, with or without cardio pulmonary bypass. These pumps provide a continuous flow sufficient to ensure the theoretical cardiac output. The Heartmate 2 Investigators group compared the use of a pneumatic pump, the Heartmate ${ }^{\circ}$, to a continuous flow pump, the Heartmate $\mathrm{II}^{\circ}$. After two years, the survival with the pneumatic pump was $24 \%$ against $58 \%$ with the continuous flow pump ( $p=0.008$ ) [7]. These results showed that, in addition to the technical advantages (small size, electrical energy), there is an advantage in terms of 
survival for the patients, and the continuous flow pumps are more and more the first choice for the patients with a left ventricle failure. Thanks to technical progress made on development of pumps and the experience in management of complications, LVADs are accepted as one of the major tools to treat the cardiac failure, either as bridge to transplantation or to recovery (even if the rate of explant due to recovery is low) or as a definitive therapy (destination) [8-10].

\section{Problems and Complications of Current Pumps}

The main complications observed in the Interagency Registry for Mechanically Assisted Circulatory Support (INTERMACS) are infection (17,46\%), bleeding (16,5\%), cardiac arrhythmia (7,68\%), respiratory failure $(4,5 \%)$, neurological dysfunction $(2,87 \%)$, renal dysfunction $(2,48 \%)$, device malfunction $(1,98 \%)$ and right heart failure $(1,89 \%)$. Mortality under assistance is close to $20 \%$, and is related to cardiac failure, infection, CNS event, multi - organ failure and respiratory failure [11].

There are also unregistered complications due to apical implantation of axial flow pumps, such as thrombosis of the left ventricular outflow tract or the aortic valve, the risk of postoperative bleeding, and difficult explantation of the LVAD in the event of transplantation or recovery. In addition, these systems are not usable in case of bi ventricular failure.

\section{Anatomical Problems (Pocket, Cannula, Exit Cannula)}

a) The implant of an axial flow pump requires the preparation of a pocket at pre-peritoneal level, in front of the diaphragm. For large patients there is no limitation, but the implantation of the pump may be limited in small patients.

b) The in-flow cannula is placed in the apex of the left ventricle. The heart muscle forms two spirals that make up the ventricles. An under - endocardial spiral turns to the right and a sub - epicardial spiral turns to the left [12]. During ventricular dilatation, these spirals unfold and expand, but keep their shape. Once the assistance is in place, the ventricle is unloaded, they must return to their normal size to recover ventricular function. The cannula in the apex can interfere with normal contraction and, in addition, constitute a scar that affects the recovery of the contractile function of the ventricle.

c) The out-flow line of the pumps consists of a prosthetic tube anastomosed directly into the aorta. He can bend and stick to the sternum.

\section{Technical Problems (Bleeding, Adhesions)}

Bleeding and tamponade can affect more than one fifth of patients undergoing assistance. These complications may concern the suture lines, the apex of the left ventricle, as well as the anastomosis of the prosthetic tube on the aorta. Currently, "bridge to transplantation" accounts for $80 \%$ of indications for ventricular assistance. Indeed, most patients will eventually be re-operated. Postoperative adhesions become a frequent and serious problem, which increases the operating time, the risks inherent to the detachment of the heart with an increased risk of postoperative bleeding, transfusions, and could affect the post transplant survival [13].

\section{Infections}

The large implantation area of the pumps and the fluid possibly accumulated around can facilitate bacterial adhesion and multiplication. This susceptibility, in combination with heart failure, malnutrition, and immunosuppression state, makes infection the most frequent complication of mechanical circulatory assistance [10, 14]. Infections associated with LVADs can be local (the drive line, the pocket, the scar, the sternum and the mediastinum) or haematogenous (sepsis, endocarditis, pump), they can affect $20 \%$ of patients at six months, and were related to $16,2 \%$ of deaths $[10,14]$.

\section{Tromboses, Embolism And Valve Problems}

Thrombus and neurological events, including ischemic stroke, hemorrhagic stroke, and transient ischemic attack, are relatively common and often severe complications following LVAD placement. Thromboembolic complication rates range from 3\% to $20 \%$ and are related to the duration of the asistance [15]. The frequent sites of thrombosis are the connection of the conduits to the pump, both the inlet and the outlet, and particularly the suture rings of the tubes to the vascular system. Reilly et al. published a retrospective study of 51 consecutive patients receiving left ventricular assistance over a 2 -year period. In this series, transesophageal echocardiography showed ventricular thrombus in 8 patients (16\%). Predictors of thrombosis were: infarction, atrial cannulation and postoperative bleeding. The presence of thrombus is associated with four times the risk of stroke compared to patients without thrombi. Ventricular cannulation and short duration of assistance may decrease the incidence of LV thrombosis [16]. Thrombosis of the aortic valve and the ascending aorta may also occur after the implantation of a LVAD despite adequate anticoagulation. This is more common in patients with a prosthetic valve, continuous flow devices and devices with grafts anastomosed on the descending thoracic aorta. In addition, the lack of left ventricular ejection with persistent closure of the aortic valve creates stagnation at this level and contributes to thrombosis [17]. Commissural fusion of the native aortic valve frequently occurs with increasing frequency of aortic insufficiency during continuous flow assistance. The impact of valvular lesion in long-term assisted patients as a bridge to transplantation or as a definitive therapy is unclear. Aortic stenosis may be a real problem for patients in whom assistance has been posed as a bridge to recovery or in those in whom assistance is unsuccessful [18-20].

\section{Advantages and Disadvantages of A Pump in the Aortic Valve Position}

\section{Anatomical, Technical and Physiological Advantages}

- The placement by vertical median sternotomy reduces the risk of bleeding and postoperative pain, as well as the duration of the procedure. Even the pump could be implanted by mini sternotomy (superior parcial sternotomy) reducing post operative pain.

- Implantation technique is the equivalent of aortic valve replacement, and thus largely known by all surgeons: a single line of suture, without apical approach of the ventricle, nor aortic anastomosis, also reducing the risk of bleeding: reproducible technique. 
- The size of the machine would allow its implantation in patients of all sizes. There is no material to put in place in a pocket.

- The absence of a pocket to place the device would reduce the risk of associated infection.

- The "anatomical" position of the pump would allow physiological ventricular emptying, maintaining flow through the left ventricular outflow tract, and anterograde flow at the ascending aorta and coronary arteries.

- Anterograde emptying may reduce the risk of intracardiac or valvular thrombosis, and reduce the risk of systemic embolism.

- Because of the absence of an apical scar and scars, the ventricular geometry would not be modified, and the ventricular contraction (during or after the weaning) would be more effective.

- Implantation in the intracardiac valve position would eventually lead to dual aortic and pulmonary implantation in the event of bi-ventricular failure.

- In case of transplantation, the absence of strong apical pericardial adhesions, the absence of aortic prosthetic tube and the fully intra-cardiac position of the machine, would allow a "classical cardiectomy", with removal of the system and the heart in one. "Block".

- In the event of ventricular function recovery, there would be no ventricular scar and no loss of myocardial mass and the aortic valve would be replaced by a conventional prosthesis, similar to an aortic valve redux.

\section{Disadvantages}

- The operative technique demanded the use of CPB and aortic clamping. Today CPB is considered a safe and low risk technique that allows complex and long-lasting procedures on the heart. In addition, the majority of devices, except the Jarvik $2000^{\circ}$, are implanted under $\mathrm{CPB}$ with lateral clamping of the aorta to anastomose the prosthetic tube.

- The implantation of the device requires sacrifice of the aortic valve and its replacement in case of recovery.

- Implantation in the aortic position makes the assistance the only way of ventricular ejection, and thus implies absolute reliability of the device. There are several causes of device malfunction, including thrombus formation with hemolysis, mechanical failure of the impeller, and driveline lead fractures with electrical failure. Current continuous-flow

- devices consisting of only a single, nearly moving part-the impeller- sowed in clinical trials, statistically significant lower pump replacement rates in comparison to their first and second generation counterparts.

- Even if the rate of device malfunction is low, in the event of a technical problem a massive aortic insufficiency would occur and the ventricle would have no ejection channel and the patient would die. A mechanism, such as an internal valve, should be found to protect the heart in the event of a technical problem with the machine.
- There are the same disadvantages common to all electrical pumps, the transcutaneous passage of an activation line for the power supply. The Jarvik 2000 the activation line pass through the thorax, the neck and comes out retro-ear position. This technique has greatly decreased cable site infections and represents a great advance in decreasing this complication.

\section{Valvular Pumps}

\section{The Valvo Pump}

The idea of an aortic valve pump was first published by Yoshinori Mitamura ,in Japan, in 1991. Mitamura and his colleagues developed a small axial flow pump (33 mm length, $37 \mathrm{~mm}$ diameter) capable of generating a flow of $6.91 / \mathrm{min}$ and a differential pressure of $48 \mathrm{~mm}$ Hg. Initial studies showed the feasibility of the pump [21]. In 1999 the Mitamura team released a final pump model of $44 \mathrm{~mm}$ in length, and $38 \mathrm{~mm}$ in external diameter. This pump was experimentally tested in a closed circuit and was able to operate for 41 days without stopping, to generate a flow of $5 \mathrm{~L} / \mathrm{min}$ at $7000 \mathrm{rpm}$ and did not to produce too much haemolysis [22]. Unfortunately, the size of the Mitamura pump does not allow its implantation in vivo.

\section{The Dynamic Aortic Valve}

Li and coworkers, at the Department of Cardiac Surgery, Institute of Cardiology and Fu Wai Hospital, Beijing, and the Union Medical College and the Chinese Academy of Medical Science, Beijing, China, have also developed an axial flow pump implanted in aortic position [23]. Since the device is intended for long-term use, the motor and pump unit are physically separated. The device consists of a finned wheel and a rotor contained in a cage. The magnetic rotor rotates in the presence of alternating magnetic fields produced by an electric motor. The pump is sutured to the aortic ring. The assembly also includes a valve that maintains the proper hemodynamics through the aortic port. A prototype was manufactured and evaluated in vitro. It was capable of delivering a flow rate up to $5 \mathrm{~L} / \mathrm{min}$ with a rotation rate of $12,600 \mathrm{rpm}$ with a differential pressure of $100 \mathrm{mmHg}$.

\section{Intraventricular Axial Flow Pump}

Yamazaki et al, in the Department of Cardiovascular Surgery, Tokyo Women's Medical College, Heart Institute, Japan, and later in the Medical Center at the University of Pittsburgh, USA, have developed a ventricular assist axial flow pump left fully implantable in the left ventricle [24]. The system consists of a finned wheel $(13.9 \mathrm{~mm})$, combined with a guide fin, a tube housing and a motor. The pump is made of titanium alloy and the weight of the pump is $170 \mathrm{~g}$. It produces a flow of more than $5 \mathrm{~L} / \mathrm{min}$ against $100 \mathrm{~mm} \mathrm{Hg}$ of pressure at 9,000 rpm, with a total power consumption of $8 \mathrm{~W}$. The maximum total efficiency exceeds $17 \%$. The pump was implanted in the LV cavity trough the apex and passes the aortic valve. Blood is drained from the VG to the intake ports at the pump base and discharged into the ascending aorta. In an animal model, three pumps were implanted in three cases (26, 30 and 168 days of assistance). The operation of the pump remained stable during all experiments. No cardiac arrhythmias were detected, even during stress tests in these 3 cases. Plasma free hemoglobin level remained within acceptable 
limits. The post mortem examination did not reveal any interference between the pump and the mitral apparatus. No thromboembolism was detected in the vital organs in Cases 1 and 2 , but some small renal infarctions were detected in case 3 [25]. Due to anatomical problems, and conditioning, the pump was not considered a durable device.

\section{Cross-valvular cannular pump}

Kun Xi Qian at the Institute of Biomedical Engineering of Jiangsu University, China, in association with the University of Texas, USA, built a ventricular energy transduction pump totally implantable in the left ventricle [26]. The device has a motor and a pump completely contained in a cannula. The motor has a coil with an iron core and a rotor with the four-pole magnet; the pump has a finned wheel and a flow guide fin. The dimensions of the engine are $60 \mathrm{~mm}$ in length and $13 \mathrm{~mm}$ diameter. The dimensions of the pump are $55 \mathrm{~mm}$ in length and $11 \mathrm{~mm}$ in diameter. The total length of the device is 115 millimeters. The total weight of the device is $53 \mathrm{~g}$. The use bearing motor supports eight needles on each side of the rotor magnets. A special purge system is provided by infusion of saline mixed with heparin in the pump inlet chamber (30 - $50 \mathrm{cc}$ per hour). Thus no mechanical wear or thrombus formation was observed during use of this pump. During the hemodynamic experiment, the pump produced a flow of $4 \mathrm{~L}$ / minute with a pressure increase of $60 \mathrm{mmHg}$, at a speed of 12500 $\mathrm{rpm}$. At zero flow, corresponding to the diastolic period of the heart, the pump can maintain the aortic pressure at more than $80 \mathrm{mmHg}$ at the same rotational speed. According to the authors, this new pump can be quickly inserted in an emergency and removed easily after the recovery of the native heart and may be useful for patients with acute left ventricular failure.

\section{The “USJ - III Aortic Valvo Pump}

The same authors have also developed other pump intended to be implanted in aortic position [27]. Like those described previously, it consists of a cylindrical steel box which contains a stator and a rotor activated by external magnetic field. The pump has a weight of $40 \mathrm{~g}$ and an outer diameter of $25 \mathrm{~mm}$. around the pump is a flange to allow its attachment to the aortic ring. It operates at three speeds: 10000 , 12500 and $15000 \mathrm{rpm}$. The prototype of the pump was tested in an experimental model in vitro for four months. The power consumption is $7 \mathrm{~W}$ at $15000 \mathrm{rpm}$, it has been able to generate a maximum flow of $10 \mathrm{~L} / \mathrm{min}$ (range 4 -10) and pressures of $80 \mathrm{~mm} \mathrm{Hg}$, parameters which are quite satisfactory for support human hemodynamics. The authors developed other $23 \mathrm{~mm}$ diameter prototype with a weight of $31 \mathrm{~g}$, tested in vitro and implanted in a pig of $80 \mathrm{~kg}$ [28]. Finally the same team has developed a pump of $21 \mathrm{~mm}$ diameter for weight of $27 \mathrm{~g}$ that operates at three speeds $(12500,15000$ and $17500 \mathrm{rpm}$ and was capable of generating a flow of $5 \mathrm{~L} / \mathrm{min}$ in vitro [29]. Until today, this pump is the smallest and most advanced in the world. Currently the authors are working to improve the biocompatibility of this pump and ensure its durability.

\section{Discussion \& Conclusion}

The idea of implanting a pump in the aortic position is not recent. Several tests have been done over the last 20 years to manufacture a pump with a size that allows its implantation in aortic position and the power adequate to support the hemodynamics of a human being. These efforts are still in an experimental stage, but there are already small pumps in development, and it is likely that in future years the improvement of their biocompatibility and durability will allow their human implantation. It is also probable that after some modifications of the current pumps these could be put in place in aortic position. If the theoretical benefits are real, probably this new generation of pumps will hold a place among the audience of the future, especially by their ease of implementation. Different anticoagulation protocols will have to show if there are any advantages for this type of implantation on the thrombotic risk. In addition, one can imagine a double implantation (aortic and pulmonary) for bi ventricular failure.

\section{Acknowledgement}

[List here any individuals who contributed in the work and grant details.]

\section{Abbreviations}

LVAD: left ventricle assist device.

CPB: cardio pulmonary bypass

CVA: cerebrovascular accident

CNS: Central nervous system

LV: Left ventricle

\section{References}

1. Ponikowski P, Voors A, Anker S, Bueno H, Cleland J, et al. (2016) Guia ESC 2016 sobre el diagnóstico y tratamiento de la insuficiencia cardiaca aguda y crónica. Rev Esp Cardiol 69: 1119-1125.

2. Nicolini F, Gherli T (2009) Alternatives to transplantation in the surgical therapy for heart failure. Eur J Cardiothorac Surg 35: 214-228.

3. Tjang YS, van der Heijden GJ, Tenderich G, Grobbee DE, Körfer R (2008) Survival analysis in heart transplantation: results from an analysis of 1290 cases in a single center. Eur J Cardiothorac Surg 33: 856-861.

4. de Jonge N, Kirkels JH, Klöpping C, Lahpor JR, Caliskan K, et al. (2008) Guidelines for heart transplantation. Neth Heart $J$ 16: 79-87.

5. De Bakey M (2005) Development of Mechanical Heart Devices. Ann Thorac Surg 79: $2228-2231$.

6. Rose EA, Gelijns AC, Moskowitz AJ, Heitjan DF, Stevenson LW, et al. (2001) Long-term mechanical left ventricular assistance for end-stage heart failure. $N$ Engl J Med 345: 1435-1443.

7. Slaughter M, Rogers J, Milano C, Russell S, Conte JV, et al. (2009) Advanced Heart Failure Treated with Continuous-Flow Left Ventricular Assist Device. NEngl J Med 361: 2241-2251.

8. Baughman K, Jarcho A (2007) Bridge to Life -- Cardiac Mechanical Support. $N$ Engl J Med 357: 846-849.

9. Topkara VK, Garan AR, Fine B, Godier-Furnemont AF, Breskin A, et al. (2016) Myocardial Recovery in Patients Receiving Contemporary Left Ventricular Assist Devices: Results From the Interagency Registry for Mechanically Assisted Circulatory Support (INTERMACS). Circ Heart Fail 9: e003157.

10. Kirklin JK, Naftel DC, Pagani FD, Kormos RL, Stevenson L, et al. (2012) Longterm mechanical circulatory support (destination therapy): on track to compete with heart transplantation?. J Thorac Cardiovasc Surg 144: 584-598.

11. Kirklin JK, Naftel DC, Kormos RL, Stevenson LW, Pagani FD, et al. (2010) Second INTERMACS annual report: more than 1,000 primary left ventricular assist device implants. J Heart Lung Transplant 29: 1-10.

12. Sengupta PP, Korinek J, Belohlavek M, Narula J, Vannan MA, Khandheria BK et al. (2006) Left ventricular structure and function: basic science for cardiac imaging. J Am Coll Cardio 48:1988-2001.

13. Patolla V, Patten R, Denofrio D, Konstam MA, Krishnamani R, et al. (2009) The effect of ventricular assist devices on post transplant mortality in analysis of the United Network for organ sharing thoracic registry. J Am Coll Cardiol 5:264-271. 
14. Holman W, Pamboukian S, Blood M, Tallaj J, McGiffin D, et al. (2005) Managing Device Infections: Are We Progressing or Is Infection an Insurmountable Obstacle?. ASAIO Journal 51: 452-455.

15. McIlvennan CK, Magid KH, Ambardekar AV, Thompson JS, Matlock DD, et al. (2014) Clinical outcomes after continuous-flow left ventricular assist device: a systematic review. Circ Heart Fail 7: 1003-1013.

16. Reilly M, Wiegers S, Cucchiara A, O'Hara ML, Plappert T, et al. (2000) Frequency, risk factors, and clinical outcomes of left ventricular assist device-associated ventricular thrombus. The American Journal of Cardiology 86: 1156-1159.

17. Crestanelloa J, Orsinellib D, Firstenberga M, Sai-Sudhakara C (2009) Aortic valve thrombosis after implantation of temporary left ventricular assist device. Interactive CardioVascular and Thoracic Surgery 8: 661-662.

18. Mudd JO, Cuda JD, Halushka M, Soderlund KA, Conte JV, et al. (2008) Fusion of aortic valve commissures in patients supported by a continuous axial flow left ventricular assist device. J Heart Lung Transplant 27: 1269-1274.

19. Rose AG, Park SJ, Bank AJ, Miller LW (2000) Partial aortic valve fusion induced by left ventricular assist device. Ann Thorac Surg 70: 1270-1274.

20. Connelly JH, Abrams J, Klima T, Vaughn WK, Frazier OH (2003) Acquired commissural fusion of aortic valves in patients with left ventricular assist devices. $J$ Heart Lung Transplant 22: 1291-1295.

21. Mitamura Y, Yozu R, Tanaka T, Yamazaki K. (1991) The valvo-pump. An axial, nonpulsatile blood pump. ASAIO Trans 37: M510-512.

22. Mitamura Y, Nakamura H, Okamoto E, Yozu R, Kawada S, et al. (1999) Development of the valvo pump: An axial flow pump implanted at the heart valve position. Artif Organs 23: 566-571.
23. Li GR, Ma WG, Zhu XD (2001) Development of a new left ventricular assist device: the dynamic aortic valve. ASAIO J 47: 257-60.

24. Yamazaki K, Umezu M, Koyanagi H, Outa E, Ogino S, Otake Y, et al. (1993) Development of a miniature intraventricular axial flow blood pump. ASAIO J 39: 224-230.

25. Yamazaki K, Kormos RL, Litwak P, Tagusari O, Antaki JF, Kameneva M, et al (1997) Long-term animal experiments with an intraventricular axial flow blood pump. ASAIO J 43: 696-700

26. Qian KX, Wang DF, Topaz S, Ru WM, Zeng P, et al. (2007) Novel totally implantable trans-ventricular and cross-valvular cannular pump with rolling bearings and purge system for recovery therapy. Journal of Medical Engineering \& Technology 131: 10-13.

27. Qian KX, Wang DF, Topaz S, Zeng P, Yuan HY, et al. (2005) World-first implantable aortic valvo pump (IAVP) with sufficient haemodynamic capacity. Journal of Medical Engineering \& Technology 6: 302-304.

28. Qian KX (2006) An implantable aortic valvo-pump for destination therapy. Cardiovasc Eng 6: 41-43.

29. Qian K X, Wang D F, Topaz S, Ru W M, Zeng P, et al. (2007) World-smallest LVAD with $27 \mathrm{~g}$ weight, $21 \mathrm{~mm}$ OD and $51 \mathrm{~min}-1$ flow with $50 \mathrm{mmHg}$ pressure increase. Journal of Medical Engineering \& Technology 31: 181-184.

Citation:

Enrique Seguel (2019) Implantation of Continuous Flow Pumps in Aortic Valve Position: Theoretical Advantages and Disadvantages. J Cardiol Clin Pract Volume 2(1): $1-5$. 